\title{
Optimum allocation of conservation funds and choice of conservation programs for a set of African cattle breeds
}

\author{
Sabine B. REIST-MARTI ${ }^{\mathrm{a} *}$, Awudu ABDULAI ${ }^{\mathrm{b}}$, Henner SIMIANER $^{\mathrm{c}}$ \\ ${ }^{a}$ Institute for Agricultural Economics, Swiss Federal Institute of Technology, Zurich, \\ Switzerland and Department of Animal Science, Swiss College of Agriculture, Zollikofen, \\ Switzerland \\ ${ }^{\mathrm{b}}$ Department of Food Economics and Consumption Studies, University of Kiel, Kiel, Germany \\ ${ }^{\mathrm{c}}$ Department of Animal Breeding and Genetics, University of Goettingen, Goettingen, \\ Germany
}

(Received 15 May 2005; accepted 16 August 2005)

\begin{abstract}
Although funds for livestock conservation are limited there is little known about the optimal allocation of conservation funds. A new algorithm was used to allocate Mio US\$ $1,2,3,5$ or unlimited funds, discounted over 50 years, on 23 African cattle breeds conserved with four different possible conservation programs. Additionally, Mio US\$ 1 was preferably allocated to breeds with special traits. The conceptional in situ conservation programs strongly involve breeders and give them part of the responsibility for the conservation of the breed. Therefore, the pure in situ conservation was more efficient than cryoconservation or combined in situ and cryoconservation. The average annual discounted conservation cost for a breed can be as low as US\$ 1000 to US\$ 4400 depending on the design of the conservation program and the economic situation of the country of conservation. The choice of the breeds and the optimal conservation program and the amount of money allocated to each breed depend on many factors such as the amount of funds available, the conservation potential of each breed, the effects of the conservation program as well as its cost. With Mio US\$1, 64\% of the present diversity could be maintained over 50 years, which is $13 \%$ more than would be maintained if no conservation measures were implemented. Special traits could be conserved with a rather small amount of the total funds. Diversity can not be conserved completely, not even with unlimited funds. A maximum of $92 \%$ of the present diversity could be conserved with Mio US\$10, leaving $8 \%$ of the diversity to unpredictable happenings. The suggested algorithm proved to be useful for optimal allocation of conservation funds. It allocated the funds optimally among breeds by identifying the most suited conservation program for each breed, also accounting for differences in currency exchange rates between the different countries.
\end{abstract}

optimal allocation / conservation program / African cattle / conservation funds / choice of program

* Corresponding author: sabine.reist@alumni.ethz.ch 


\section{INTRODUCTION}

About $30 \%$ of all farm animal breeds worldwide are at a risk of extinction. Funds for conservation of breed diversity are limited and not sufficient to conserve all breeds.

Several authors have examined the choice of breeds according to their endangerment (e.g. $[8,21])$ or their endangerment and contribution to diversity $[15,18,27-30]$. In other studies the cost of different conservation programs and their effects $[1,13,14,17,24-26]$ have been analyzed.

Yet, research on how to use the limited funds on the breeds most efficiently, i.e. with the highest conserved diversity possible is scarce. Such allocation of funds must include the choice of breeds, conservation programs and shares of the total budget spent on each breed.

Simianer [22] and Simianer et al. [23] proposed a new algorithm for the optimal allocation of conservation funds. Simianer [22] compared the algorithm with giving equal shares to all breeds, or giving $1 / 3$ of the funds to the three most endangered breeds, respectively, and found in an application to 23 African cattle breeds that the cost efficiency of conservation is increased by about $60 \%$ when funds are optimally allocated. In those analyses, it was assumed that the same functions linking conservation cost to conservation effects apply for all breeds. Reist-Marti et al. [19] analyzed designs, cost and benefits of possible conservation schemes and suggested, based on empirical results, more specific functions for a set of 23 African cattle breeds.

The general decision making and allocation problem therefore needs to be extended. Given that a defined amount of funds is available for this purpose, it is necessary to specify:

(a) which breeds should be chosen for active conservation measures;

(b) which conservation strategy will be applied to any one of the chosen breeds; and

(c) what is the optimal size of the chosen conservation scheme (e.g. number of individuals included in an in vivo or in vitro scheme).

The primary objective of this study is to present a methodology that will provide answers to these three questions. The algorithm will be illustrated with the same set of 23 African cattle breeds used in the studies mentioned before. In addition, it will be shown how the relative value of special traits can be quantified, i.e. how much conserved diversity needs to be sacrificed to conserve a certain proportion of one or multiple special traits present in the set of breeds considered. 


\section{METHODS}

\subsection{Functional relationship between conservation cost and returns}

The suggested methodology is an extension of the method described in detail by Simianer et al. [23]. In this study, the change in extinction probability, $\Delta z_{i}$, of breed $i$ is considered to be a continuous function of the actual extinction probability, $z_{i}$, and the amount of funds spent for conservation in this breed, $m_{i}$, i.e.

$$
\Delta z_{i}=f\left(z_{i}, m_{i}\right),
$$

where $\Delta z_{i}=z_{i}^{*}-z_{i}$ and $z_{i}^{*}$ is the extinction probability after the conservation activity has taken place. Note that $\Delta z_{i}<0$ since $z_{i}^{*}<z_{i}$. Simianer et al. [23] suggested three mathematically continuous and steady functions reflecting different conservation schemes. However, neither discontinuities nor economic realities like fixed cost of a conservation program are taken into account by these functions.

We suggest using an alternative function $z_{i}^{*}=f\left(z_{i}, m_{i}\right)$, which overcomes these problems. This function is based on the approach suggested by ReistMarti et al. [18] using a scoring system to derive extinction probabilities, with

$$
z_{i}=a+b \sum_{j=1}^{N} s_{i j}
$$

where $s_{i j}$ is a score indicating whether effect $j$ affecting the degree of endangerment of breed $i$ is present or not, and $a, b$ are appropriately chosen constants to scale $0<z_{i}<1$.

Note, that following [18] $a$ and $b$ should be chosen such that the breed is neither entirely safe $\left(z_{i}=0\right)$ nor guaranteed to become extinct $\left(z_{i}=1\right)$ in the time horizon considered. The effects affecting the degree of endangerment can be population size, sociocultural importance, or geographic distribution of the breed, where always the unfavourable condition is indicated by a higher score. The assumed mechanism of a conservation scheme is that it removes or reduces some of the factors affecting the degree of endangerment. If, for example, a breed is originally geographically concentrated in a region threatened by natural disasters like droughts, and conservation funds are used to re-locate a part of the population to a less endangered area, the score for 'geographic distribution' will be reduced. 
Mathematically this means that for some $j$ the score after implementation of the conservation scheme $s_{i j}^{*}<s_{i j}$ and

$$
z_{i}^{*}=a+b \sum_{j=1}^{N} s_{i j}^{*}<z_{i} .
$$

Different conservation programs will affect different components of the degree of endangerment. This is obvious, when in situ live conservation and in vitro cryoconservation are compared. Different programs will also have different costs, which are a combination of fixed cost (necessary to establish the program) and variable cost (depending on the number of animals conserved). At the same time, the reduction in the degree of endangerment will be proportional to the number of animals included in the scheme.

This will be illustrated with an example. Consider a hypothetic breed with a given set of variables indicating the actual level of endangerment (Tab. I). The ten variables are taken from Reist-Marti et al. [18]. Using the constants $a=0.1$ and $b=0.66$, the resulting actual extinction probability is $z_{i}=0.63$.

Now consider a conservation program $P$, which has positive effects on a number of variables. This conservation program can be conducted on various levels. The lowest level $P_{L}$ has the cost $C_{P_{L}}=$ Mio $\$ 0.037$ and reduces the factors total population size, degree or risk of indiscriminate crossing, established conservation scheme and reliability of information, so that the resulting extinction probability is $z_{i}^{P_{L}}=0.37$. The highest level $P_{H}$ has the cost $C_{P_{H}}=$ Mio $\$ 0.078$ and reduces the factors total population size, distribution of the breed, degree or risk of indiscriminate crossing, established conservation scheme and reliability of information, so that the resulting extinction probability is $z_{i}^{P_{H}}=0.33$. We assume, that intermediate levels can be generated by a linear extrapolation. It should be clear, that $C_{P_{L}}=$ Mio $\$ 0.037$ is the minimum sum that has to be spent in this conservation scenario, mainly reflecting fixed cost. It should also be noted that there will be no additional effect by spending more than $C_{P_{H}}=$ Mio $\$ 0.078$.

An alternative conservation scheme $Q$ is considered, again with two levels $Q_{L}$ and $Q_{H}$, with cost $C_{Q_{L}}=$ Mio $\$ 0.058$ and $C_{Q_{H}}=$ Mio $\$ 0.100$ and resulting extinction probabilities $z_{i}^{Q_{L}}=0.27$ and $z_{i}^{Q_{H}}=0.23$.

For both scenarios, the functions between conservation expenditure and extinction probability are depicted in Figure 1. From this function, the choices depending on the available conservation budget for this breed are clear:

(a) if the budget is < Mio \$ 0.037: do not invest in this breed, because there will be no conservation effect;

(b) if the budget is between Mio \$ 0.037 and Mio $\$ 0.058$ : use program $P$, 
Table I. The effects of the low $(L)$ and high $(H)$ cost scenarios of two conservation programs $P$ and $Q$ on the extinction probability of a breed $\left(z_{i}\right)$.

\begin{tabular}{lccccc}
\hline & & \multicolumn{5}{c}{ Breed conserved with } \\
& $\begin{array}{l}\text { Breed not } \\
\text { conserved }\end{array}$ & & & & \\
\cline { 5 - 7 } & & $P_{L}$ & $P_{H}$ & $Q_{L}$ & $Q_{H}$ \\
\hline Variable & & & & & \\
Total population size & 0.30 & 0.20 & 0.20 & 0.10 & 0.10 \\
Change of total population size 0.10 & 0.10 & 0.10 & 0.10 & 0.10 & \\
over the last 10 years & & & & & \\
Distribution of the breed & 0.10 & 0.10 & 0.05 & 0.05 & 0 \\
Degree or risk of indiscriminate & 0.10 & 0 & 0 & 0 & 0 \\
crossing & & & & & \\
Organization of farmers & 0 & 0 & 0 & 0 & 0 \\
Established conservation & 0.10 & 0 & 0 & 0 & 0 \\
scheme & & & & & \\
Political situation of the country/-ies & 0 & 0 & 0 & 0 & 0 \\
(average over all countries) & & & & & \\
Special traits & 0 & 0 & 0 & 0 & 0 \\
Sociocultural importance & 0 & 0 & 0 & 0 & 0 \\
Reliability of the information & 0.10 & 0 & 0 & 0 & 0 \\
Total & 0.80 & 0.40 & 0.35 & 0.25 & 0.20 \\
Extinction probability $z_{i}^{\mathrm{a}}$ & 0.63 & 0.37 & 0.33 & 0.27 & 0.23 \\
Maximum cost $C$ (in Mio US\$) & & 0.037 & 0.078 & 0.058 & 0.100 \\
\hline
\end{tabular}

${ }^{\mathrm{a}} z_{i}=(($ Total $) \times(0.8 / 1.2))+0.1$. For details see [19].

because this is the only feasible program with that budget;

(c) if the budget is between Mio $\$ 0.058$ and Mio $\$ 0.100$ : use program $Q$, because it gives you a better return than program $P$;

(d) if the budget is $>$ Mio $\$ 0.100$ : use Mio $\$ 0.100$ to implement $Q_{H}$ and use the rest in another breed, because you will not get any additional effect by spending more than $C_{Q_{H}}$.

As is demonstrated with the dotted line in Figure 1, the two curves (or in general as many curves as different conservation schemes are considered) can be combined in one function linking conservation expense in this breed both to a choice of conservation scheme and a quantification of returns in terms of reduced extinction probability. In the remaining presentation this function will be denoted as $F\left(m_{i}\right)$.

If e.g. Mio $\$ 0.080$ should be allocated to this breed, the function $F\left(m_{i}\right)$ both specifies that the optimal conservation scheme is scheme $Q$ and the resulting extinction probability is 0.25 . 


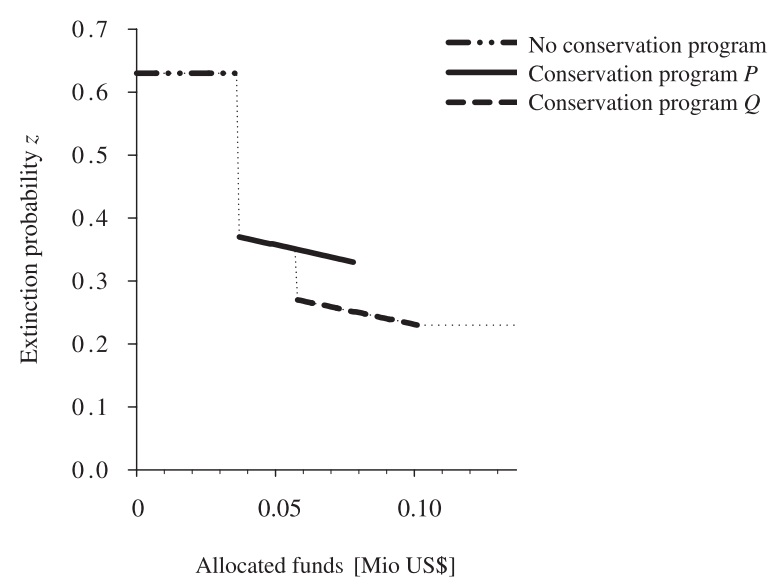

Figure 1. The cost efficiency of the conservation programs $P$ and $Q$ and the optimal allocation function (dotted line) for a breed. The optimal allocation function indicates which conservation program is most efficient subject to the funds allocated to the breed.

\subsection{Optimum allocation of funds}

Consider a situation where a total budget $B$ should be optimally allocated to a set of $N$ breeds. Let $\mathbf{M}$ be a vector of length $N$ where element $m_{i} \geq 0$ reflects the amount of money spent on conservation of breed $i$ and $\sum m_{i}=B$. Let $\mathbf{Z}$ be a vector of size $N$ containing extinction probabilities of the $N$ breeds, with $z_{i}$ being the extinction probability of breed $i$ in a given time period $t$ without any conservation measures. By a given allocation pattern defined through $\mathbf{M}$, $\mathbf{Z}$ is modified to $\mathbf{Z} \mid \mathbf{M}$ with element $z_{i}^{*}<z_{i}$ for at least some $i$. Note, that for a given $m_{i}$ both the reduced extinction probability and the optimum choice of conservation program is determined through the function $F\left(m_{i}\right)$ for that breed. Hence, a certain $\mathbf{M}$ specifies both the allocation pattern and the choice of conservation program in every single breed. Adopting the method suggested by Simianer et al. [23], it is straightforward to calculate the expected Weitzman diversity $E(D \mid \mathbf{M})$ conditional on the allocation pattern.

Let $\mathbf{J}$ be a vector of size $\mathrm{N}$ containing the indicator variables $j_{i}, i=1, \ldots N$, where $j_{i}=1$ if breed $i$ is still existing and $j_{i}=0$ if it is extinct at a given point of time. Hence, $\mathbf{J}$ reflects a situation where a subset of the total breeds is still existing and the complementary subset is extinct.

The probability that a specific situation, characterized through a specific vector $\mathbf{J}$, arises under the allocation pattern $\mathbf{M}$ can be computed as

$$
P(\mathbf{J} \mid \mathbf{M})=\prod_{i}\left(j_{i}+(-1)^{j_{i}} z_{i}^{*}\right) .
$$


From the above, $2^{N}$ different combinations of present and extinct breeds are possible, for which the respective probabilities can be computed as described.

Let $D_{J}$ be the Weitzman diversity [28] of the set of breeds not extinct, i.e. with $j_{i}=1$ in vector $\mathbf{J}$. Then, the expected diversity at the end of the assumed time period can be computed as

$$
E(D \mid \mathbf{M})=\sum_{\forall J} P(\mathbf{J} \mid \mathbf{M}) D_{J} .
$$

The objective thus is to find the vector $\mathbf{M}$ with $\sum m_{i}=B$ which leads to the maximum value of $E(D \mid \mathbf{M})$.

Simianer et al. [23] propose a stepwise algorithm using marginal diversities to find the optimum allocation. This approach is not feasible with the suggested function $F\left(m_{i}\right)$, because this function is no longer steady and monotonically decreasing. If $e . g$. the allocated shares are less than the fixed cost of any conservation design in any breed, the algorithm will not be able to allocate the first share to any breed.

As an alternative, a two-step algorithm is suggested. In the first step, the optimum number of conserved breeds is derived under the assumption that the total budget is allocated in equal shares to all selected breeds. If the budget is divided in $K<<N$ equal shares, the conservation budget for each selected breed will cover fixed and variable cost to a sufficient extent. As was shown above, the budget allocated to any one breed automatically determines the conservation scheme to be conducted in this breed being the scheme with optimum cost efficiency at the defined investment level. In the second step, the optimum unbalanced allocation is derived in the subset of breeds chosen to be conserved in the first step.

In step one of the suggested method, we use the following algorithm:

1. We start assuming that all breeds will be conserved by dividing the total budget $B$ in $N$ equal shares. Technically, this is done by setting $m_{i}=B / N$ for all breeds $i$, the resulting vector is called $\mathbf{M}_{N}$. Using this allocation vector, we compute $E\left(D \mid \mathbf{M}_{N}\right)$.

2. We calculate all values $E\left(D \mid \mathbf{M}_{N-1}\right)$, where $B$ is divided in $N-1$ equal shares and allocated to all but one breeds. Since one out of $N$ breeds can be left out at a time, we get $N$ different results of $E\left(D \mid \mathbf{M}_{N-1}\right)$, of which we store the maximum value and the corresponding allocation vector.

3. Of the remaining $N-1$ breeds, we again leave out one at a time and generate all possible allocation vectors $\mathbf{M}_{N-2}$ having $N-2$ elements $m_{i}=B /(N-2)$ and two zero elements. Again, the maximum value for $E\left(D \mid \mathbf{M}_{N-2}\right)$ and the corresponding allocation vector is stored. 
This algorithm is continued, until the value $E\left(D \mid \mathbf{M}_{K}\right)$ exceeds $E\left(D \mid \mathbf{M}_{K-1}\right)$, showing that a uniform allocation to $K$ breeds gives a higher expected Weitzman diversity than a uniform allocation to $K-1$ breeds. $K$ then is identified as the optimum number of breeds, $N_{\text {opt }}$ under a balanced allocation.

In most cases, $N_{\text {opt }}$ will take an intermediate value. If many breeds are chosen, all of them will receive little funding and a large proportion of the funds will be used to cover the fixed cost of many conservation programs. If on the other side all the conservation budget is allocated to just one breed, this breed will be made as safe as possible, but the endangerment of all other breeds remains unchanged. Since both extreme scenarios appear to be suboptimal, the optimum balanced allocation will be for an intermediate number of breeds, i.e. $1<N_{\text {opt }}<N$.

In step two, the optimum unbalanced allocation among the breeds selected in step one is found by the following algorithm:

We start with any vector $\mathbf{M}_{K}$ reflecting allocation of the total funds to a subset of $N_{\text {opt }}$ breeds. Among these we chose at random two breeds $i$ and $j$. We then take a small share $b$ from the conservation budget of breed $i$, changing $m_{i} \rightarrow m_{i}-b$, and reallocate this share to breed $j$, changing $m_{j} \rightarrow m_{j}+b$. With the modified allocation vector $\mathbf{M}_{K}^{\prime}$ we compute $E\left(D \mid \mathbf{M}_{K}^{\prime}\right)$. If this value is larger than the expected diversity $E\left(D \mid \mathbf{M}_{K}\right)$ with the original vector, we accept this reallocation, if $E\left(D \mid \mathbf{M}^{\prime}{ }_{K}\right)<E\left(D \mid \mathbf{M}_{K}\right)$, we undo the reallocation. This step is repeated until no increase in $E\left(D \mid \mathbf{M}_{K}\right)$ occurs any more.

This algorithm is not necessarily finding the global optimum. Therefore it is useful to restart it repeatedly with different random number seeds. It also may result in an optimum allocation which does not include all breeds that were in the optimal balanced subset with equal shares, so it may end up with a subset of size $<N_{\text {opt }}$, while it technically never can add new breeds. Therefore it is recommended to start this algorithm also with the suboptimal balanced allocation vectors of size $N_{o p t}+1$ and $N_{o p t}-1$.

\subsection{Consideration of special traits}

The objective of livestock conservation is not only to conserve diversity, but also to conserve special traits which may be present in one or several breeds. In the most general case, one may wish to conserve several special traits, present in different breeds, simultaneously.

The basic assumption here is that a special trait is a characteristic of entire breeds. This means, that the trait is conserved if at the end of the planning 
horizon at least one breed has survived that carries this trait, and that the trait is lost if all breeds carrying this trait have disappeared.

The indicator variable $x_{i t}=1$ if breed $i$ carries trait $t$ and $x_{i t}=0$ if not. We suggest two different summary statistics to quantify the amount of special traits in a given set of breeds which is specified through the vector $\mathbf{J}$ as described earlier.

(a) The variable $T_{1}$ reflects the number of breeds showing special traits, summed over all traits, and is defined as $T_{1} \mid \mathbf{J}=\sum_{t} \sum_{i} j_{i} x_{i t}$.

(b) The variable $T_{2}$ indicates how many special traits are present in at least one of the breeds present in subset $\mathbf{J}$. For this, we have to define a variable $\tau_{t}$ which is

$$
\tau_{t}=\left\{\begin{array}{lll}
1 & \text { if } & \sum_{i} j_{i} x_{i t}>0 \\
0 & \text { if } & \sum_{i} j_{i} x_{i t}=0
\end{array} .\right.
$$

Then, $T_{2} \mid \mathbf{J}=\sum_{t} \tau_{t}$.

If, for example, special trait one is present in breed A, B, and C, special trait two is present in breed $\mathrm{C}$ and $\mathrm{D}$, and special trait three is present in breed $\mathrm{D}$, then $T_{1}=6$ and $T_{2}=3$ in the total set of all breeds. If the subset $J=[1,1,1,0]$ is considered, $T_{1} \mid J=4$, because the traits two and three expressed in breed D are disregarded, and $T_{2} \mid J=2$, because trait three, which is only expressed in breed $\mathrm{D}$, is not present in this subset.

Diversity and either of the two special trait statistics can be combined in one objective function by a weighted summation. As suggested in Simianer [22], we call this a utility function defined as

$$
U_{J}=w_{1} D_{J}+w_{2} T_{l} \mid \mathbf{J}
$$

where $l=1$ or 2 and $w_{1}$ and $w_{2}$ are appropriately defined relative weights of diversity and special trait statistics, respectively. Conditional on an allocation vector $\mathbf{M}$, the expected utility can be computed as

$$
E(U \mid \mathbf{M})=\sum_{\forall J} P(\mathbf{J} \mid \mathbf{M}) U_{J}
$$

and the algorithm suggested to find allocation vector $\mathbf{M}$ maximizing the expected diversity can be used straightforwardly to maximize the expected utility. 


\subsection{Computational aspects}

In the proposed methodology it is necessary to repeatedly calculate the expected diversity of the total set of $N$ breeds. The following arguments are equally valid for the calculation of an expected utility, but will be shown for the case of expected diversity only.

When using the algorithm suggested by Simianer et al. [23] the computing time for one calculation of $E(D \mid \mathbf{M})$ is proportional to $2^{N}$, which may be prohibitive for large sets of breeds.

In the second step of the allocation algorithm suggested above, only a subset of $N_{\text {opt }}$ extinction probabilities is variable, while extinction probabilities for the $N-N_{\text {opt }}$ breeds not getting any financial support for conservation are fixed. In the following, it is shown how the expected diversity in this case can be calculated much more efficiently and rapidly.

Let us assume that the first $N_{v}$ breeds have variable extinction probabilities $z_{i}^{*}$ conditional on $\mathbf{M}$ while the extinction probability of the remaining $N_{f}$ breeds is fixed as $z_{i}$.

Let $\mathbf{V}$ be a vector of size $N_{v}$ containing the indicator variables $v_{i}, i=$ $1, \ldots N_{v}$, where $v_{i}=1$ if breed $i$ is still existing and $v_{i}=0$ if it is extinct at a given point in time. Correspondingly, $\mathbf{F}$ is a vector of size $N_{f}$ describing the presence or absence of those breeds with fixed extinction probabilities, containing the indicator variables $f_{i}, i=1, \ldots N_{f}$, where $f_{i}=1$ if breed $i$ still exists and $f_{i}=0$ if it is extinct. Hence, $\{\mathbf{V}, \mathbf{F}\}$ reflects a situation where a subset of the total breeds still exists and the complementary subset is extinct. Note that the vector $\mathbf{J}$ defined earlier is equivalent to $\{\mathbf{V}, \mathbf{F}\}$.

The probability that a specific situation, characterized through a specific vector $\{\mathbf{V}, \mathbf{F}\}$, arises with allocation vector $\mathbf{M}$ can be computed as:

$$
\begin{aligned}
P(\mathbf{V}, \mathbf{F} \mid \mathbf{M}) & =\prod_{i=1}^{N_{v}}\left(v_{i}+(-1)^{v_{i}} z_{i}^{*}\right) \prod_{i=1}^{N_{f}}\left(f_{i}+(-1)^{f_{i}} z_{N_{v}+i}\right) \\
& =P(\mathbf{V} \mid \mathbf{M}) \times P(\mathbf{F}) .
\end{aligned}
$$

Let $D_{V, F}$ be the diversity of the set of breeds not extinct in a specific scenario described through $\{\mathbf{V}, \mathbf{F}\}$. 
Then, the expected diversity at the end of the assumed time period can be computed as

$$
\begin{aligned}
& E(D \mid \mathbf{M})=\sum_{\forall \mathbf{V}, \mathbf{F}} P(\mathbf{V}, \mathbf{F}) D_{V, F} \\
= & \sum_{\forall \mathbf{V}, \mathbf{F}} P(\mathbf{V} \mid \mathbf{M}) \times P(\mathbf{F}) \times D_{V, F} \\
= & \sum_{\forall \mathbf{V}} P(\mathbf{V} \mid \mathbf{M}) \times\left[\sum_{\forall \mathbf{F}} P(\mathbf{F}) D_{V, F}\right] .
\end{aligned}
$$

Since $P(\mathbf{F})$ is invariant over the possible allocation alternatives leading to changes in $Z$, the term $\sum_{\forall \mathbf{F}} P(\mathbf{F}) D_{V, F}$ has to be computed for each possible vector $\mathbf{V}$ only once. Different allocation patterns are reflected in different values of the elements in $P(\mathbf{V} \mid \mathbf{M})$, so that summations still have to be done over the $2^{N_{v}}$ different vectors $\mathbf{V}$.

This reduces computing time substantially: with $N=23$ breeds and a subset of $N_{v}=8$ breeds receiving conservation funds, the necessary computing time to calculate $E(D)$ for one allocation pattern is reduced by the factor $2^{-\left(N-N_{v}\right)}=$ $3.05 \times 10^{-5}$.

\subsection{DATA}

\subsubsection{Breeds}

The genotypes of 23 African cattle breeds are used for illustration, which all are of zebu (Bos indicus) and zenga (Bos indicus $\times$ Bos taurus) type. They are further described in Table II and [4, 9, 10, 18, 23]. To avoid confusion and mingling of breeds or strains having the same name, it is assumed that the country of conservation is equal to the origin of the blood sample (Tab. II). For further detail see [9] and [18]. For Arashie (Beja), Sudan was chosen as the country of conservation in accordance with information on the origin of the breed given by [6].

Most of the breeds are reported to have one or several of the following special traits (Tab. II): trypanotolerance, tick/disease resistance, hardiness, adaptation to the local environment, docile/calm temperament, high fertility, good mothering ability and high product quality.

In this application, the relative weight for special traits was defined in such a way, that the utility of a set of breeds was increased by a quarter of a standard deviation of expected diversity for each special trait shown by a breed represented in the set. This weight was chosen arbitrarily, but allowed to quantify the relative equivalence of conservation of special traits compared to the conservation of neutral diversity. 
Table II. The name and its abbreviation of African cattle breeds, their country of conservation and its exchange ratio from international \$ to US\$ (PPP/OER) and the breeds' special traits.

\begin{tabular}{|c|c|c|c|c|c|c|c|c|}
\hline \multirow{2}{*}{ Breed } & \multirow{2}{*}{ Abbreviation } & \multirow{2}{*}{$\begin{array}{l}\text { Country of } \\
\text { conservation }\end{array}$} & \multirow{2}{*}{$P P P / O E R^{\mathrm{a}}$} & \multicolumn{5}{|c|}{ Trait $^{b}$} \\
\hline & & & & 12 & 3 & 45 & 67 & 78 \\
\hline Angoni & ANGONI & Zambia & 0.46 & & $\mathrm{X}$ & $X$ & & \\
\hline Arado & ARADO & Eritrea & $0.29^{c}$ & & & $X$ & & \\
\hline Arashie (Beja) & ARASHIE & Sudan & 0.20 & & & $\mathrm{X}$ & & \\
\hline Arsi & ARSI & Ethiopia & 0.12 & & & & & \\
\hline Bale & BALE & Ethiopia & 0.12 & & & & & \\
\hline Ethiopian Boran & ETHBORAN & Ethiopia & 0.12 & & & X X & $\mathrm{X}$ & $x$ \\
\hline Butana & BUTANA & Sudan & 0.20 & & & & & \\
\hline Fogera & FOGERA & Ethiopia & 0.12 & & & $\mathrm{X}$ & & \\
\hline Gobra & GOBRA & Senegal & 0.31 & & & $\mathrm{X}$ & & \\
\hline Highland Zebu & HIGHZEBU & Kenya & 0.38 & & & & & \\
\hline Horro & HORRO & Ethiopia & 0.12 & & & $\mathrm{X}$ & & \\
\hline Iringa Red & IRINGARED & Tanzania & 0.52 & & & $X$ & & \\
\hline Kavirondo & KAVIRONDO & Kenya & 0.38 & & & & & \\
\hline Kenyan Boran & KENYBORAN & Kenya & 0.38 & $\mathrm{X}$ & x & $\mathrm{X}$ & X X & $x$ \\
\hline Kilimanjaro Zebu & KILIMANJA & Tanzania & 0.52 & & & & & \\
\hline Malawi Zebu & MALAZEBU & Malawi & 0.29 & & & & & \\
\hline Maure & MAURE & Mauritania & 0.18 & & & $\mathrm{X}$ & & \\
\hline Mbororo & MBORORO & Nigeria & 0.37 & & & & & $X$ \\
\hline Nuba Mountain & NUBA & Sudan & 0.20 & $\mathrm{X}$ & & & & \\
\hline Ogaden & OGADEN & Ethiopia & 0.12 & & & & & \\
\hline Orma Boran & ORMABORAN & Kenya & 0.38 & $\mathrm{X}$ & & $\mathrm{X}$ & & \\
\hline Sokoto Gudali & SOKOTO & Nigeria & 0.37 & & & & & \\
\hline Madagascar Zebu & MADAZEBU & Madagascar & 0.35 & & $\mathrm{X}$ & & & $\mathrm{X}$ \\
\hline
\end{tabular}

${ }^{a} P P P$ : Purchasing Power Parity conversion factor to the international $\$$ and OER: Official Exchange Rate to the US\$ of the local currency in year 2001 [33].

b 1: trypanotolerance; 2: tick/disease resistance; 3 : hardiness; 4: adapted to local environment; 5: docile/calm temperament; 6: fertile; 7: good mothering ability; 8: good product quality. Source: $[6,7,11]$.

${ }^{\mathrm{c}}$ No $P P P$ conversion factor available for Eritrea in 2001. Assumption: average ratio of $P P P / O E R$ over all breeds $(=0.29)$.

\subsubsection{Design of the conservation programs}

In situ, ex situ and combined (in/ex situ) conservation programs running over 50 years were modeled. For each conservation program a low and a high input (cost) scenario was calculated. Low input scenario means that only a minimum 
is invested to have a certain conservation effect. Hence, cost is mainly a fixed cost. High input scenario results in a substantial conservation effect at the price of a higher variable cost. Reist-Marti et al. [19] describe the modeled conservation programs in detail; a summary is given below (low/high input scenarios are separated by " "”):

- HB For the in situ conservation program HB, a herdbook is installed and events (e.g. sales, competitions or courses) are organized to promote the breed and motivate breeders to keep this breed. It is assumed that 168/252 animals are registered in the first year with an annual increase in registered animals of $10 \%$. Two/four events are organized per year and the effective population size is assumed to remain constant over the 50 years.

- IS The in situ conservation program IS consists of a circular mating scheme, where sires rotate between 10/30 cow groups. Each group consists of five cows and one sire. The cows are owned by farmers and the sires belong to the program. The sires and cows are replaced by one of their offspring every fifth year when the rotation of sires takes place.

- CC For the ex situ conservation program CC semen from 25/75 unrelated sires is cryoconserved. The breed is reactivated by backcrossing from another breed with artificial insemination over six generations (27 years) resulting in 58 cows having $98 \%$ of the genes from the cryoconserved breed. It is assumed that time to first calving is four years [31], the calving interval is two years $[2,20,32]$ and the survival rate of the offspring is $70 \%[2,20,32]$.

- IC The combined in situ and cryoconservation program starts with a base population of 320 unrelated animals ( 300 cows, 20 sires) of the breed. Additionally $25 / 75$ sires not related to this founder generation of the base population are cryoconserved and used for artificial insemination on half of the cows every fifth year, i.e. once per generation. The other half of the cows of the base population are mated with the sires from the base population. Cows and sires are replaced by their offspring.

\subsubsection{Cost of conservation programs}

The basic assumption underlying this study is that a transnational budget of a fixed size is available and should be allocated to the populations in the different countries such that the expected conserved diversity or utility is maximized. To overcome biases due to different market structures and economic levels in the countries of conservation, Reist-Marti et al. [19] suggested using the international dollar (I\$) to calculate and compare cost of conservation programs. The international dollar is not a real currency but a measure for the 
purchasing power (standardized to the US market) necessary to buy a certain good,

$$
I \$=\frac{L C}{P P P},
$$

with $P P P=1$ for the US\$; $L C=$ local currency.

Hence, Reist-Marti et al. [19] compared the purchasing power of the money needed to setup and run different conservation programs. To illustrate we assume that in Zambia a conservation program $P$ cost Mio Kwacha (K) 3290. In the US the same program $P$ cost Mio US\$ 2. Hence, the Mio K 3290 on the Zambian market are equivalent to Mio US\$ 2 on the US market as the same good, i.e. the conservation program $P$, was bought. This relation of the purchasing power of a local currency on a local market with the US\$ on the US market is given by the purchasing power parity conversion factor PPP. The $P P P$ issued by the World Bank [33] is derived by comparing prices in different countries and the US for a certain basket of goods.

Different to Reist-Marti et al. [19], biases in cost for different countries due to their market structure and economic level should be considered in this study. Therefore, the cost of the different conservation programs given by Reist-Marti et al. [19] is converted from I\$ to the local currency of the country of conservation using the PPP of the year 2002 given by the World Bank [33]. It is further assumed that funding is paid in US\$. Hence, it must be calculated how much the program would cost in US\$. Therefore, the conservation cost (in local currency) is converted to US\$ using the official exchange rate $\left(O E R=\frac{L C}{U S \$}\right)$ of the country of conservation [33] and rounded to Mio US\$ 0.001. The OER for Zambia is 3610.94. Hence, the conservation program $P$ costing Mio K 3290 would need Mio US\$ 0.091112 (rounded to Mio US\$ 0.091) for funding.

The translation from I\$ to US\$ getting the currency translation effect reflecting the economic situation of the country of conservation can be done directly with the ratio $P P P / O E R$ given in Table II. The missing $P P P / O E R$ ratio for Eritrea was assumed to be 0.29 , which is the average ratio of $P P P / O E R$ for all breeds (Tab. II).

In the remainder of this paper we will refer to the US\$ as \$.

\subsubsection{Effects of conservation programs}

The effects of a conservation program are measured as reduced endangerment, i.e. lowered extinction probability as defined by Reist-Marti et al. [18]. Reist-Marti et al. [19] estimated the effects of the conservation programs on a hypothetical breed having a maximum extinction probability of $90 \%$. In this 
study, the expected effects on the extinction probability of the low and high cost scenarios of the four conservation programs HB, IS, CC and IC are estimated for each of the 23 African cattle breeds individually. Consider, as an example, breed $i$ with an extinction probability $z_{i}=0.63$. In Table I, column one gives the value for each variable if the breed is not conserved. Column two shows the maximum values of the ten variables and the resulting extinction probability $z_{i}^{P_{L}}$ when the low cost scenario of the conservation program $P$ is applied to breed $i$.

For certain breeds it occured that the low and high cost scenarios of a conservation program resulted in the same extinction probability $\left(z_{i}^{P_{L}}=z_{i}^{P_{H}}\right)$. Since the algorithm needs a difference between $z_{i}^{P_{L}}$ and $z_{i}^{P_{H}}, z_{i}^{P_{H}}$ was reduced by 0.1 after rescaling (not shown in Tab. I). This slight overestimation of the cost efficiency of the conservation programs will not have a substantial impact on the results since it is equally effected for all conservation programs and breeds.

\subsubsection{Funds for conservation}

It is assumed that either unlimited funds or a hypothetical amount of Mio $\$ 1,2,3$ or 5 is provided for conservation. For modeling the conservation of special traits, conservation funds of Mio $\$ 1$ are assumed. The total amount is split up in 200 equal shares $(b)$ for allocation.

Conservation programs vary in the time the money is spent. To account for this, all expenses were discounted with an interest rate of $3 \%$. The aforementioned total amounts therefore reflect the present discounted value. Assuming an equal distribution over the planning horizon of 50 years, an annual investment of Mio \$ 0.037733 , and summing up to Mio \$ 1.886650 over 50 years, would be equivalent to Mio \$ 1 discounted. All sums in the remaining text refer to the present discounted values.

\section{RESULTS}

\subsection{Cost of conservation programs}

Table III shows the conservation cost of each breed with different programs. The lowest conservation cost was Mio \$ 0.048 for in situ conservation (IS) in Ethiopia of the Arsi, Bale, Ethiopian Boran, Fogera, Horro and Ogaden breed. The highest cost caused combined in situ/ex situ conservation (IC) of the Iringa Red and Kilimanjaro Zebu in Tanzania (Mio \$ 1.683). The cost ranged from Mio \$ 0.062 to Mio \$ 0.781 for the herdbook conservation program HB, from 
Table III. Conservation cost for African cattle breeds with different conservation programs (in US\$1000).

\begin{tabular}{|c|c|c|c|c|c|c|c|c|}
\hline \multirow{3}{*}{ Breed } & \multicolumn{8}{|c|}{ Conservation program $^{\mathrm{a}}$} \\
\hline & \multicolumn{2}{|c|}{ HB } & \multicolumn{2}{|c|}{ IS } & \multicolumn{2}{|c|}{$\mathrm{CC}$} & \multicolumn{2}{|c|}{$\mathrm{IC}$} \\
\hline & low & high & low & high & low & high & low & high \\
\hline ANGONI & 237 & 687 & 187 & 708 & 259 & 585 & 855 & 1480 \\
\hline ARADO & 152 & 438 & 119 & 257 & 165 & 374 & 546 & 945 \\
\hline ARASHIE & 105 & 304 & 83 & 313 & 114 & 259 & 379 & 656 \\
\hline ARSI & 62 & 178 & 48 & 184 & 67 & 152 & 222 & 384 \\
\hline BALE & 62 & 178 & 48 & 184 & 67 & 152 & 222 & 384 \\
\hline ETHBORAN & 62 & 178 & 48 & 184 & 67 & 152 & 222 & 384 \\
\hline BUTANA & 105 & 304 & 83 & 313 & 114 & 259 & 379 & 656 \\
\hline FOGERA & 62 & 178 & 48 & 184 & 67 & 152 & 222 & 384 \\
\hline GOBRA & 164 & 474 & 129 & 489 & 179 & 404 & 591 & 1023 \\
\hline HIGHZEBU & 197 & 570 & 155 & 587 & 215 & 486 & 710 & 1228 \\
\hline HORRO & 62 & 178 & 48 & 184 & 67 & 152 & 222 & 384 \\
\hline IRINGARED & 270 & 781 & 212 & 805 & 294 & 665 & 973 & 1683 \\
\hline KAVIRONDO & 197 & 570 & 155 & 587 & 215 & 486 & 710 & 1228 \\
\hline KENYBORAN & 197 & 570 & 155 & 587 & 215 & 486 & 710 & 1228 \\
\hline KILIMANJA & 270 & 781 & 212 & 805 & 294 & 665 & 973 & 1683 \\
\hline MALAZEBU & 152 & 438 & 119 & 452 & 165 & 374 & 546 & 945 \\
\hline MAURE & 96 & 278 & 76 & 287 & 105 & 237 & 347 & 600 \\
\hline MBORORO & 195 & 564 & 153 & 581 & 212 & 480 & 702 & 1215 \\
\hline NUBA & 105 & 304 & 83 & 313 & 114 & 259 & 379 & 656 \\
\hline OGADEN & 62 & 178 & 48 & 184 & 67 & 152 & 222 & 384 \\
\hline ORMABORAN & 197 & 570 & 155 & 587 & 215 & 486 & 710 & 1228 \\
\hline SOKOTO & 195 & 564 & 153 & 581 & 212 & 480 & 702 & 1215 \\
\hline MADAZEBU & 180 & 520 & 141 & 537 & 196 & 444 & 648 & 1122 \\
\hline
\end{tabular}

${ }^{\text {a }}$ For further description of the conservation programs see text.

Mio \$ 0.048 to Mio \$ 0.805 for in situ conservation with sire rotation (IS), from Mio \$ 0.067 to Mio \$ 0.665 for cryoconservation (CC) and from Mio \$ 0.222 to Mio $\$ 1.683$ for the combined conservation program (IC).

The highest average conservation cost due to the economic and political situation of the country (high ratio $P P P / O E R$ ) resulted for Tanzania $(P P P / O E R=0.52)$, followed by Zambia (0.46) and Kenya (0.38); the lowest average cost resulted for Ethiopia (0.12), Mauritania (0.18) and Sudan (0.20). 
Table IV. Effects of different conservation programs applied to African cattle breeds given as reduced extinction probability $(z)$.

\begin{tabular}{|c|c|c|c|c|c|c|c|c|c|}
\hline \multirow{3}{*}{ Breed } & \multirow{3}{*}{$\begin{array}{l}\text { Extinction } \\
\text { probability }^{\mathrm{b}}\end{array}$} & \multicolumn{8}{|c|}{ Conservation program ${ }^{\mathrm{a}}$} \\
\hline & & \multicolumn{2}{|c|}{$\mathrm{HB}$} & \multicolumn{2}{|c|}{ IS } & \multicolumn{2}{|c|}{$\mathrm{CC}$} & \multicolumn{2}{|c|}{$\mathrm{IC}$} \\
\hline & & low & high & low & high & low & high & low & high \\
\hline ANGONI & 0.40 & 0.13 & 0.03 & 0.20 & 0.10 & 0.33 & 0.23 & 0.27 & 0.17 \\
\hline ARADO & 0.50 & 0.17 & 0.07 & 0.23 & 0.13 & 0.30 & 0.20 & 0.30 & 0.20 \\
\hline ARASHIE & 0.53 & 0.27 & 0.17 & 0.40 & 0.30 & 0.33 & 0.23 & 0.33 & 0.23 \\
\hline ARSI & 0.53 & 0.17 & 0.07 & 0.30 & 0.20 & 0.37 & 0.27 & 0.37 & 0.27 \\
\hline BALE & 0.57 & 0.17 & 0.07 & 0.30 & 0.20 & 0.37 & 0.27 & 0.37 & 0.27 \\
\hline ETHBORAN & 0.48 & 0.18 & 0.08 & 0.25 & 0.15 & 0.38 & 0.28 & 0.31 & 0.21 \\
\hline BUTANA & 0.43 & 0.17 & 0.07 & 0.27 & 0.17 & 0.30 & 0.20 & 0.33 & 0.23 \\
\hline FOGERA & 0.43 & 0.17 & 0.07 & 0.20 & 0.10 & 0.30 & 0.20 & 0.27 & 0.17 \\
\hline GOBRA & 0.37 & 0.17 & 0.07 & 0.17 & 0.07 & 0.23 & 0.13 & 0.17 & 0.07 \\
\hline HIGHZEBU & 0.70 & 0.30 & 0.20 & 0.43 & 0.33 & 0.50 & 0.40 & 0.43 & 0.33 \\
\hline HORRO & 0.43 & 0.17 & 0.07 & 0.20 & 0.10 & 0.30 & 0.20 & 0.27 & 0.17 \\
\hline IRINGARED & 0.60 & 0.20 & 0.10 & 0.33 & 0.23 & 0.40 & 0.30 & 0.33 & 0.23 \\
\hline KAVIRONDO & 0.47 & 0.17 & 0.07 & 0.27 & 0.17 & 0.30 & 0.20 & 0.27 & 0.17 \\
\hline KENYBORAN & 0.35 & 0.18 & 0.08 & 0.25 & 0.15 & 0.31 & 0.21 & 0.25 & 0.15 \\
\hline KILIMANJA & 0.63 & 0.27 & 0.17 & 0.37 & 0.27 & 0.47 & 0.37 & 0.37 & 0.27 \\
\hline MALAZEBU & 0.50 & 0.13 & 0.03 & 0.23 & 0.13 & 0.33 & 0.23 & 0.30 & 0.20 \\
\hline MAURE & 0.40 & 0.13 & 0.03 & 0.20 & 0.10 & 0.27 & 0.17 & 0.27 & 0.17 \\
\hline MBORORO & 0.37 & 0.13 & 0.03 & 0.17 & 0.07 & 0.20 & 0.10 & 0.17 & 0.07 \\
\hline NUBA & 0.57 & 0.23 & 0.13 & 0.37 & 0.27 & 0.37 & 0.27 & 0.37 & 0.27 \\
\hline OGADEN & 0.60 & 0.30 & 0.20 & 0.37 & 0.27 & 0.43 & 0.33 & 0.37 & 0.27 \\
\hline ORMABORAN & 0.40 & 0.17 & 0.07 & 0.23 & 0.13 & 0.23 & 0.13 & 0.30 & 0.20 \\
\hline SOKOTO & 0.53 & 0.17 & 0.07 & 0.27 & 0.17 & 0.37 & 0.27 & 0.33 & 0.23 \\
\hline MADAZEBU & 0.50 & 0.13 & 0.03 & 0.23 & 0.13 & 0.33 & 0.23 & 0.30 & 0.20 \\
\hline
\end{tabular}

${ }^{\text {a }}$ For further description of the conservation programs see text.

b Taken from [19].

\subsection{Effects of conservation programs}

Initially, the Kenyan Boran had the lowest $(z=0.35)$ and the Highland Zebu the highest $(z=0.70)$ extinction probability (Tab. IV). After conservation, the lowest expected extinction probability of a breed was 0.03 for Angoni, Malawi Zebu, Maure, Mbororo and Madagascar Zebu (conserved with HB high) and the highest expected extinction probability was 0.50 for the Highland Zebu conserved with $\mathrm{CC}$ low. The conservation program with the lowest impact $(\Delta z=-0.04)$ on the extinction probability was CC low for the Kenyan Boran $\left(z^{*}=0.31\right)$. The highest $(\Delta z=-0.50)$ impact on the extinction probability had HB high for Bale $\left(z^{*}=0.07\right)$, Iringa Red $\left(z^{*}=0.10\right)$ and Highland Zebu 


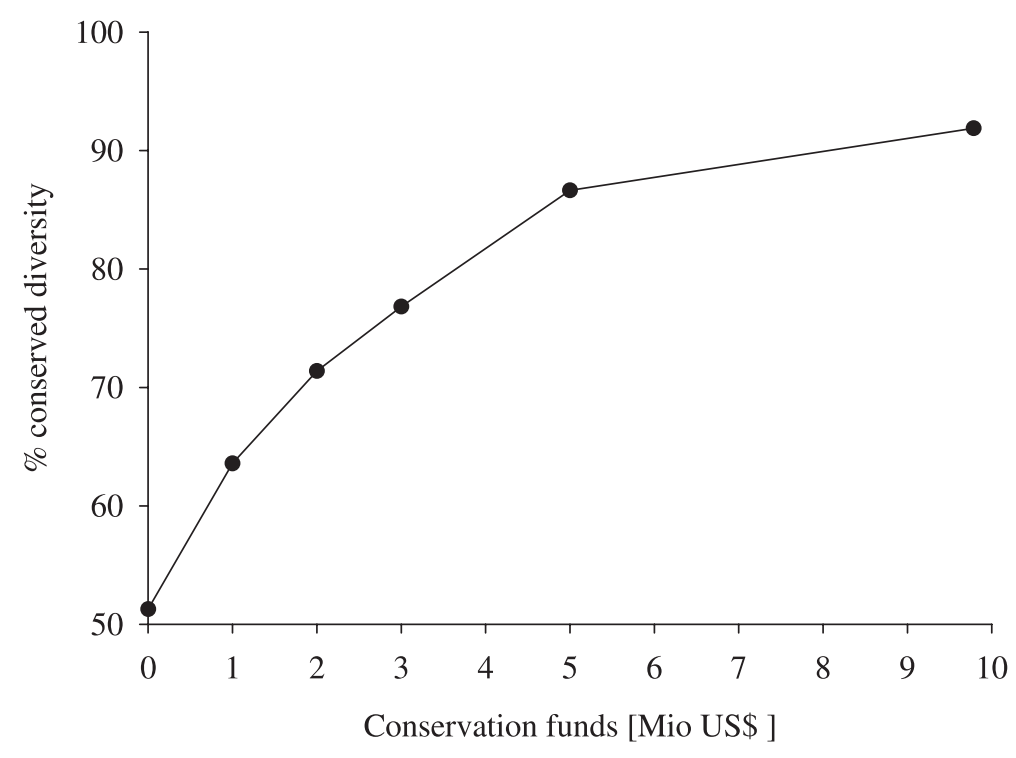

Figure 2. Conserved diversity subject to the total amount of conservation funds.

$\left(z^{*}=0.20\right)$. Each conservation program had a different effect on breeds with an equal initial extinction probability.

\subsection{Conserved diversity}

Figure 2 shows that investing Mio $\$ 0,1,2,3$ or 5 resulted in an expected diversity (percentage of present diversity in brackets) of $0.6223(51.3 \%), 0.7717$ (63.6\%), 0.8664 (71.4\%), 0.9325 (76.8\%) and $1.0516(86.6 \%)$, respectively. To conserve a maximum of diversity, i.e. 1.1151 or $91.9 \%$ of the present diversity, Mio $\$ 9.785$ would be needed. The remaining $8.1 \%$ of the diversity can not be conserved with the four conservation programs.

When a bonus was given to breeds with special traits, 63.2\% (0.7673) of the present diversity was conserved with Mio $\$ 1$. This is about $0.5 \%$ less as when diversity is conserved disregarding special traits. The total number of traits conserved in the set (variable $T_{1}$ ) was augmented from 15.953 to 17.404 $(+9.1 \%)$ by the bonus scenario and the probability of conservation of a special trait (variable $T_{2}$ ) was increased by $2.1 \%$ (Tab. V). 
Table V. Conservation of special traits in African cattle breeds with Mio US\$ 1 giving preference to breeds with special traits.

\begin{tabular}{lccccc}
\hline & \multicolumn{2}{c}{ Presence in the set of breeds } & & \multicolumn{2}{c}{ Probability of conservation } \\
\cline { 2 - 3 } \cline { 5 - 6 } $\begin{array}{c}\text { without } \\
\text { Trait }\end{array}$ & $\begin{array}{c}\text { with } \\
\text { preference }\end{array}$ & & $\begin{array}{c}\text { without } \\
\text { preference }\end{array}$ & $\begin{array}{c}\text { with } \\
\text { preference }\end{array}$ \\
\hline Trypanotolerance & 1.373 & 1.373 & & 0.909 & 0.909 \\
Tick/disease resistance & 0.650 & 0.650 & 0.650 & 0.650 \\
Hardiness & 2.746 & 2.743 & 0.996 & 0.996 \\
Adapted to local environment & 4.828 & 5.485 & 1.000 & 1.000 \\
Docile/calm temperament & 3.033 & 3.433 & 0.994 & 0.999 \\
Fertile & 0.650 & 0.650 & 0.650 & 0.650 \\
Good mothering ability & 1.170 & 1.570 & 0.832 & 0.972 \\
Good product quality & 1.503 & 1.500 & 0.953 & 0.952 \\
Total/average & 15.953 & 17.404 & 0.873 & 0.891 \\
\hline
\end{tabular}

\subsection{Amount of funds allocated to each breed}

Figure 3 displays the funds allocated to each breed for the different scenarios. With Mio \$ 1 the Madagascar Zebu, Arashie, Malawi Zebu, Nuba Mountain Zebu, Sokoto and Arsi get funds. Mio \$ 2 are most efficiently allocated to the same breeds as for the Mio \$ 1 scenario and the Bale, Ogaden, Gobra, Butana and Maure. Total funds of Mio \$ 3 were allocated to the same breeds as for Mio \$ 2 except Sokoto, plus the Highland Zebu, Mbororo, Kavirondo, Arado, Ethiopian Boran, Fogera and Horro. Mio \$ 5 and Mio \$ 9.785 were allocated to all breeds, though not with equal shares (results not shown).

Within the bonus scenario Madagascar Zebu, Arashie, Malawi Zebu, Nuba Mountain Zebu, Ethiopian Boran and Maure got money for conservation. The Kenyan Boran with most (four) special traits got no money.

Figure 4 shows the optimal allocation function for the breeds chosen for conservation with total funds of Mio $\$ 1$. The amount of money allocated to each breed by the algorithm coincides with the edges of the optimal allocation function.

\subsection{Optimal conservation programs}

The conservation programs HB and IS were generally selected as optimal by the algorithm (Fig. 4, other results not shown). 


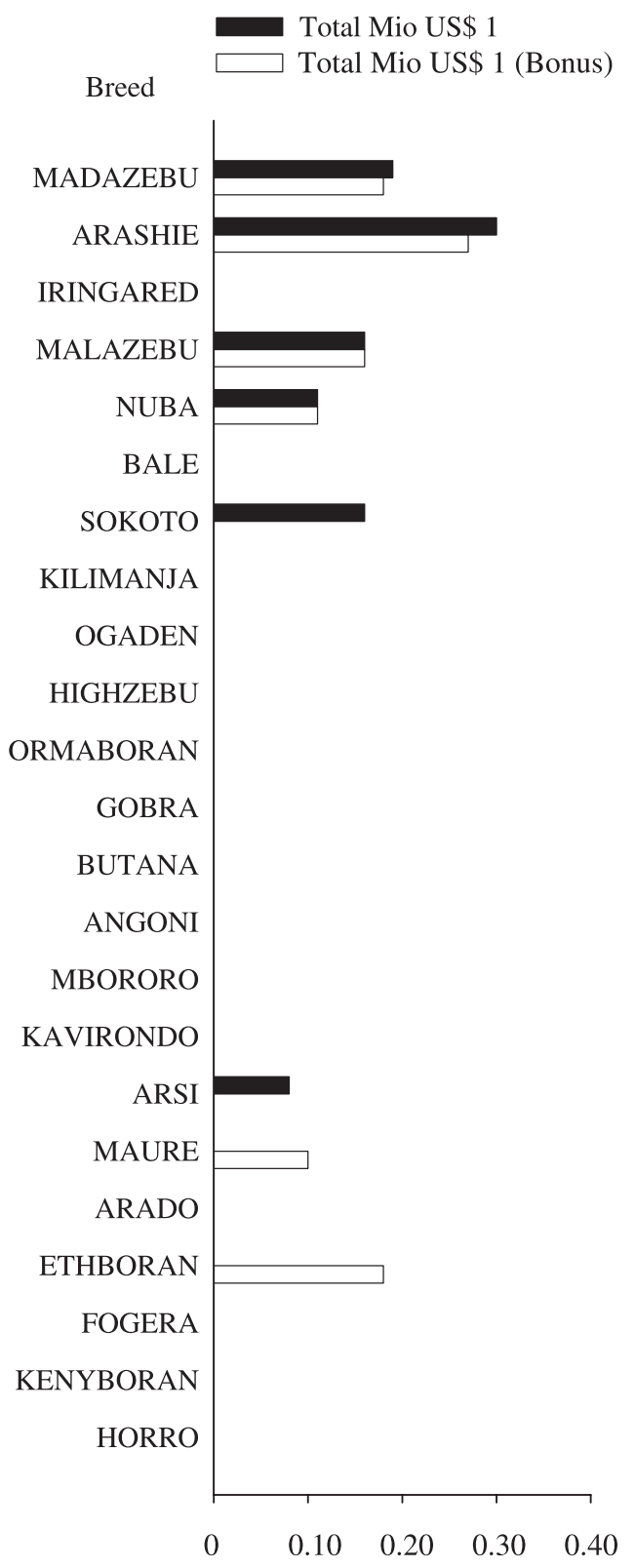

Allocated funds [Mio US\$]

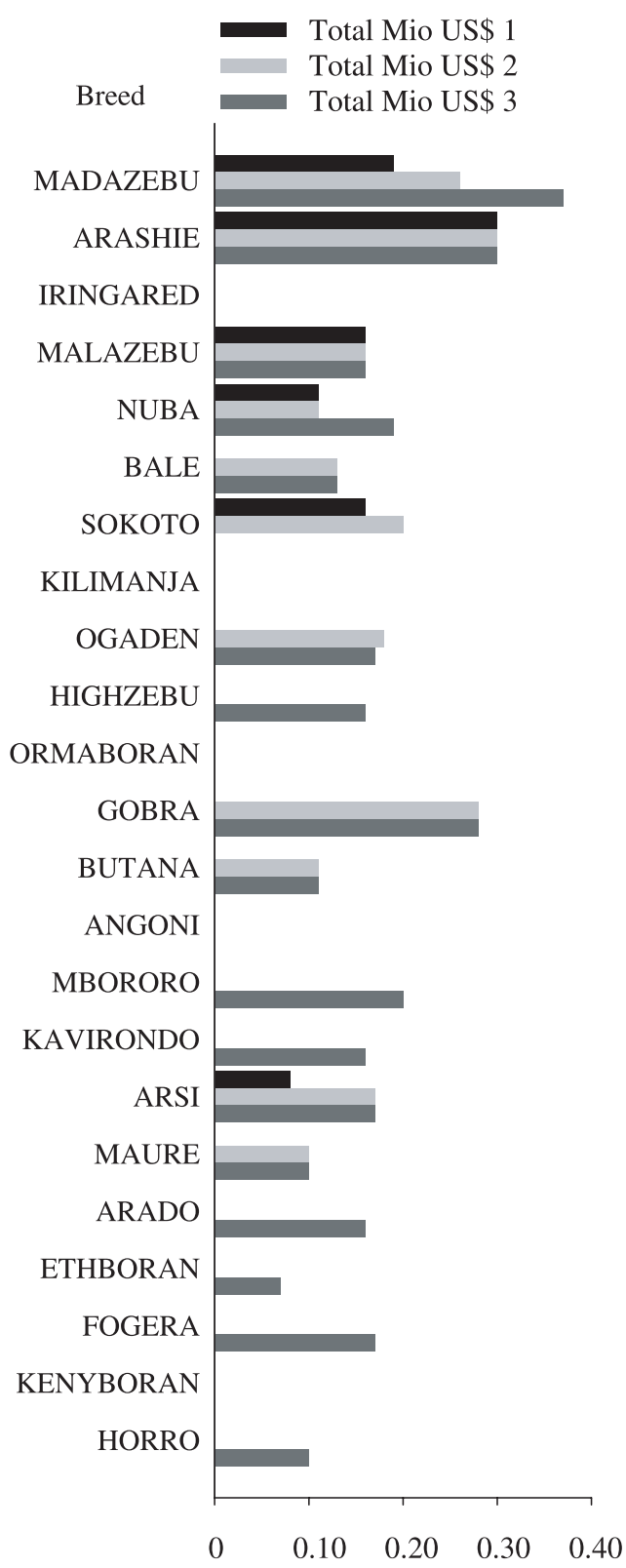

Allocated funds [Mio US\$]

Figure 3. Amount of money allocated to each breed with total funds of Mio US\$ 1, 2 and 3, respectively (for details on the bonus scenario see text). Breeds are ranged top down according to their conservation potential. 


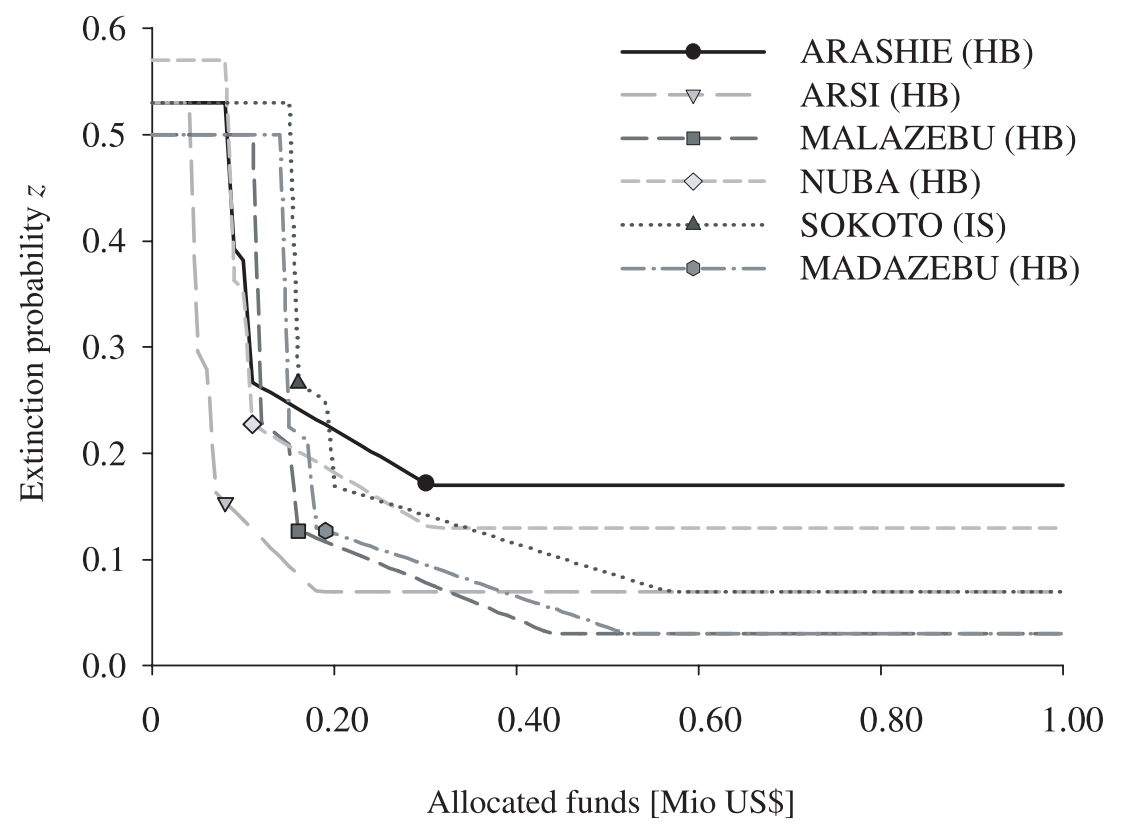

Figure 4. Optimal allocation functions of and amount of funds allocated to each breed conserved with total funds of Mio US\$1. The optimal conservation program for each breed is given in brackets (for details see text).

\section{DISCUSSION}

\subsection{Cost of conservation programs}

Reist-Marti et al. [19] showed for a hypothetical breed the wide range of conservation cost with different conservation programs. In this study, conservation cost for breeds did not only depend on the program, but also on the purchasing power parity of the local currency of the country of conservation as well as its official exchange rate to the US\$. The ratio PPP/OER varied substantially among the countries of conservation. Cryoconservation programs were more expensive than the other programs due to high fixed cost arising from the facilities needed to collect semen. Some of the countries may already have such facilities in place which could be used. However, checking the availability of facilities in each country was beyond the scope of this study. Annual average discounted conservation cost over 50 years could be as low as $\$ 1000$ for IS, \$ 1200 for HB, and \$ 1300 for CC for breeds conserved in Ethiopia (Arsi, Bale, Ethiopian Boran, Fogera, Horro, Ogaden). These costs are reasonable compared with an average annual cost of \$ 4400 for IC. However, 
depending on the country of conservation, the cost can be fourfold or more for the same conservation program. The choice of the country of conservation may depend on many factors such as infrastructure or political aspects. Yet, the countries' economic situation must not be neglected.

\subsection{Effects of conservation programs}

In the literature, the effects of conservation programs are often measured as reduced inbreeding or increased (effective) population size (e.g. [13]). Therefore, cryoconservation is proposed as one of the best conservation actions to reach this aim. In this study, the effects of the conservation programs were measured as a reduction in extinction probability $(\Delta z)$. The (effective) population size is only one among ten factors affecting $z$, though the one with the highest weight. For most breeds, the effects for HB and IS were higher than for CC and IC. Even for the most and least endangered breeds, CC was less effective than HB. While cryoconservation mainly focuses on the effective population size, in situ conservation programs such as HB and IS do have a more holistic approach. They affect many factors of the extinction probability, involve breeders and give them part of the responsibility for the conservation of the breed. Thus, they do not only increase the effective population size of the breed, but also reduce the risk of failure of conservation through promotion of the special traits and cultural embedding of the breed. The risk of failure of conservation is an important factor for the choice of a conservation program. Further research on this topic is highly needed.

\subsection{Conserved diversity and special traits}

Figure 2 shows the diminishing marginal utility of the invested funds, reaching the maximum conserved diversity at around Mio $\$ 10$ of funds. Therefore, doubling funding does not guarantee double conserved (or expected) diversity. There are about $8 \%$ of today's diversity, which can not be conserved by the conservation programs used in this study. Better conservation programs or combinations of the conservation programs considered may conserve more diversity. If the risk of failure is considered, there will always be a certain amount of diversity, which can not be conserved by any means.

It should be mentioned that this study is entirely based on the Weitzman [28] diversity measure, which recently was criticized by some authors $[3,5,16]$ to disregard the within breed diversity. This criticism is fully justified, however including within breed diversity leads to a massive conceptual complication: if within breed diversity is taken into account, we also have to model the 
change in this quantity over the assumed time horizon. Furthermore, within and between breed diversity are not independent, if within breed diversity is reduced, through a small effective population size, say, between breed diversity is increased. It will not be trivial, to derive an appropriate model reflecting this, and to implement it computationally for large breed groups. Unless such a model is operational, we feel that using Weitzman diversity is an acceptable compromise, as long as its shortcomings are kept in mind.

When giving a bonus to breeds with special traits, the expected diversity declines by 0.0043 or $0.56 \%$ to 0.7673 . This loss of about half a percent of diversity is highly compensated by an additional $9 \%$ of special traits and a gain of $2 \%$ in the average probability of conservation of a special trait.

Investing Mio $\$ 1.05$ of funds results in an expected diversity of 0.7734 (results not shown). This means that on this level of investment, 0.0018 units of expected diversity correspond to about Mio $\$ 0.05$. Hence, the special traits conserved with the bonus scenario - i.e. -0.0043 units of expected diversity do have a value of about Mio $\$ 0.12$ or $12 \%$ of the invested funds. Instead of investing these $12 \%$ of funds into $0.56 \%$ additional expected diversity, it may be worth to conserve an additional $9 \%$ of special traits. Given that the value of such special traits is known, as is the case for e.g. trypanotolerance [12] the suggested approach can be used to better assess the economic trade-off between conserving (neutral) diversity and conserving special traits of known value.

\subsection{Amount of funds allocated to each breed}

Figure 3 shows that the lower the total funds were the smaller was the number of breeds for which conservation schemes were established. Low total funds were allocated to breeds with a high conservation potential (results not shown). The conservation potential $(C P)$ is calculated as

$$
C P=m * z,
$$

where $m$ is the marginal diversity of a breed. The marginal diversity reflects the change of diversity when the extinction probability of the breed is changed by one unit $[18,23]$.

Sokoto and Mbororo are closely related breeds, which are to be conserved in countries with an equal $P P P / O E R$ ratio. With total funds of Mio $\$ 2$, Sokoto is chosen for funding due to its higher conservation potential. If more money is available (Mio \$ 3), however, Mbororo is conserved instead of Sokoto since it has a very high marginal diversity [17]. Although conservation of Mbororo 
is more costly compared to Sokoto, lowering Mbororo's extinction probability even slightly will highly increase the expected diversity of the set.

A high impact of a conservation program on the extinction probability of a breed - e.g. HB high reduces the extinction probability of Bale, Iringa Red and Highland Zebu High strongly $(\Delta z=-0.50)$ - does not guarantee for allocation of money to that breed by the algorithm.

Although Iringa Red had a high conservation potential due to its marginal diversity and high extinction probability, and showed a substantial effect of the conservation program $\mathrm{HB}$, it was not chosen for conservation with total funds of Mio \$ 3 or less due to the disadvantageous $P P P / O E R$ ratio. Hence, not only the conservation potential and the effects of the optimal conservation program are crucial for the choice of a breed, but also the program's cost, which depends on the design of the program and the economics of the country of conservation.

Breeds with low conservation cost due to a favourable economic situation of the country of conservation had a high chance of getting funds although they had a low conservation potential (e.g. Arsi).

Reist-Marti [17] showed that allocating Mio \$ 2 to one breed only or giving equal shares to all 23 breeds does not lead to a maximum of expected diversity. This result could be verified in this study. The optimal number of breeds and the optimal amount of money allocated to each breed depended on the diversity of the set of breeds, the extinction probability and conservation cost of each breed as well as the number of breeds and the amount of funds available.

Within the bonus scenario, the algorithm allocated money to the same breeds with low conservation cost and high conservation potential and many special traits as when allocating Mio \$ 1 without bonus for special traits. Furthermore, the Ethiopian Boran (three traits) and Maure (one trait) got money for conservation, both breeds representing genetically different branches from the other conserved breeds [18]. No money was allocated to the breed with the highest number of special traits, i.e. the Kenyan Boran (four traits). The conservation potential of this breed was one of the lowest and its conservation cost were high compared to the other breeds.

The new algorithm split the funds optimally among the breeds since shares were allocated to each breed only as long as a high reduction in extinction probability resulted, i.e. a steeply sloping optimal allocation function (Fig. 4).

The risk linked to the investment and changing circumstances was not considered in this study. It may happen that a cryoconserved breed never goes extinct and, hence, never has to be re-established by backcrossing. The money for backcrossing could then be spent on another breed. A conservation program 
may also fail due to internal (e.g. bad management) or external (e.g. civil unrest) reasons and the money invested is lost.

Further research on investment risk of diversity conservation is needed to be able to optimally allocate funds.

\subsection{Optimal conservation programs}

The in situ conservation programs HB and IS were often more efficient due to the various reasons mentioned above with regards to cost per reduction in extinction probability. Therefore, they were preferred as optimal conservation programs over often suggested cryoconservation programs. This result, however, pertains very specifically to the case studied and might be very different in countries where the cryoconservation infrastructure is established and can be used with little extra cost.

\section{CONCLUSIONS}

Although assumptions can always be discussed, it was shown that under realistic scenarios pure in situ conservation was more efficient than cryoconservation or combined in situ and cryoconservation. These findings for a broad application on 23 African cattle breeds are in line with the results of Reist-Marti et al. [19] for the general case of a hypothetical breed.

The choice of the country of conservation may depend on many factors such as infrastructure or political aspects, but its economic situation should also be taken into account. Average annual conservation cost for a breed could be as low as $\$ 1000$ to $\$ 4400$ for in situ and cryoconservation programs.

While the cryoconservation programs CC and IC mainly focus on high effective population sizes, the in situ conservation programs HB and IS strongly involve breeders and give them part of the responsibility for the conservation of the breed. Therefore, those programs were more efficient in lowering the extinction probability and reducing the risk of failure of conservation.

It was verified that the allocation of money is optimal for a certain number of breeds. This number depends on the diversity of the set of breeds, the extinction probability and conservation cost of each breed as well as the number of breeds and the amount of funds available. Equal allocation of funds on the breeds chosen for conservation does not lead to a maximal expected diversity. The choice of the breeds and the amount of money allocated to each breed further depends on the breed's conservation potential and the effects of the optimal conservation program as well as on the program's cost. 
It was shown that special traits can be conserved with a rather small amount of the total funds and thus, with a little waiving of expected diversity.

With a budget of Mio $\$ 1$ discounted over 50 years, $64 \%$ of the present diversity can be maintained over 50 years, which is $13 \%$ more than would be maintained if no conservation measures were implemented. However, diversity can not be conserved completely by any conservation program, not even with unlimited funds. With the conservation programs used in this study, a maximum of $92 \%$ of the present diversity could be conserved with Mio \$10, leaving $8 \%$ of the diversity to unpredictable happenings.

The suggested algorithm proved to be useful for the optimal allocation of conservation funds. It allocated the funds to diverse breeds considering the most suited conservation programs and splitting the funds optimally among breeds. However, further research in this area is needed to consider the risk of success or failure of conservation programs or changing circumstances when optimally allocating limited funds.

\section{ACKNOWLEDGEMENTS}

We kindly acknowledge the International Livestock Research Institute ILRI (Addis Ababa, Nairobi) for provision of the genotype data of the breeds and the two reviewers for the helpful comments on the manuscript.

\section{REFERENCES}

[1] Brem G., Graf F., Kräusslich H., Genetic and economic differences among methods of gene conservation in farm animals, Livest. Prod. Sci. 11 (1984) 65-68.

[2] Buck N., Light D., Lethola L., Rennie T., Mlambo M., Muke B., Beef-Cattle Breeding Systems in Botswana - the Use of Indigenous Breeds, World Anim. Rev. 43 (1982) 12-16.

[3] Caballero A., Torro M.A., Analysis of genetic diversity for the management of conserved subdivided populations, Cons. Genet. 3 (2002) 289-299.

[4] Eding H., Conservation of Genetic Diversity: Assessing Genetic Variation Using Marker Estimated Kinships, PhD thesis, Animal Breeding and Genetics Group, Department of Animal Sciences, Wageningen University, Wageningen, 2002.

[5] Eding H., Meuwissen T.H.E., Marker based estimates of between and within population kinships for the conservation of genetic diversity, J. Anim. Breed. Genet. 118 (2001) 141-159.

[6] Food and Agriculture Organization of the United Nations, DAD-IS Global Information System for Domestic Animal Diversity, version 2.0, Rome (2000) http://www.fao.org/dad-is [consulted: November 2003]. 
[7] Felius M., Cattle Breeds: An Encyclopedia, 1st edn., Misset uitgeverji bv, Doetinchem, The Netherlands, 1995.

[8] Hall S.J.G., Ruane J., Livestock breeds and their conservation: A global overview, Conserv. Biol. 7 (1993) 815-825.

[9] Hanotte O., Tawah C.L., Bradley D.G., Okomo M., Verjee Y., Ochieng J., Rege J.E.O., Geographic distribution and frequency of a taurine Bos taurus and an indicine Bos indicus Y specific allele amongst sub-Saharan African cattle breeds, Mol. Ecol. 9 (2000) 387-396.

[10] Hanotte O., Bradley D.G., Ochieng J.W., Verjee Y., Hill E.W., Rege J.E.O., African pastoralism: genetic imprints of origins and migrations, Science 296 (2002) 336-339.

[11] International Livestock Research Institute, DAGRIS Domestic Animal Genetic Resources Information System, Animal Genetic Resources Programme, International Livestock Research Institute, Nairobi, 2001.

[12] Kristjanson P.M., Swallow B.M., Rowlands G.J., Kruska R.L., de Leeuw P.N., Measuring the costs of African trypanosomosis: the potential benefits of control and returns to research, Agric. Syst. (UK) 59 (1999) 79-98.

[13] Lömker R., Erhaltung genetischer Vielfalt in-situ, ex-situ und in Kombination unter genetischen und ökonomischen Gesichtspunkten, $\mathrm{PhD}$ thesis, Institut für Tierzucht und Vererbungsforschung, Tierärztliche Hochschule Hannover, Hannover, Germany, 1993.

[14] Lömker R., Simon D.L., Costs of and Inbreeding in Conservation Strategies for Endangered Breeds of Cattle, in: Proceedings of the 5th World Congress on Genetics Applied to Livestock Production, 7-12 August 1994, Vol. 21, University of Guelph, Guelph, pp. 393-396.

[15] Metrick A., Weitzman M.L., Conflicts and choices in biodiversity preservation, J. Econ. Persp. 12 (1998) 21-34.

[16] Ollivier L., Foulley J.L., Aggregate diversity: New approach combining withinand between-breed genetic diversity, Livest. Prod. Sci. 95 (2005) 247-254.

[17] Reist-Marti S.B., Analysis of methods for efficient biodiversity conservation with focus on African cattle breeds, $\mathrm{PhD}$ thesis, Swiss Federal Institute of Technology, Zurich, 2004.

[18] Reist-Marti S.B., Simianer H., Gibson J., Hanotte O., Rege J.E.O., Weitzman's Approach and Conservation of Breed Diversity: an Application to African Cattle Breeds, Conserv. Biol. 17 (2003) 1299-1311.

[19] Reist-Marti S.B., Abdulai A., Simianer H., Conservation programs for African cattle: design, cost and benefits, J. Anim. Breed. Genet. 122 (2005) 95-109.

[20] Rennie T., Light D., Rutherford A., Miller M., Fisher I., Prachett D., Capper B., Buck N., Trail J., Beef-Cattle Productivity under Traditional and Improved Management in Botswana, Trop. Anim. Health Prod. 9 (1977) 1-6.

[21] Scherf B.D., World Watch List for Domestic Animal Diversity, 3rd edn., Food and Agriculture Organization of the United Nations, Rome, 2000.

[22] Simianer H., Noah's Dilemma: Which Breeds to Take Aboard the Ark?, in: Proceedings of the 7th World Congress on Genetics Applied to Livestock Production, 19-23 August 2002, CD-ROM communication No. 26-02, Montpellier, France. 
[23] Simianer H., Marti S.B., Gibson J., Hanotte O., Rege J.E.O., An approach to the optimal allocation of conservation funds to minimise loss of genetic diversity between livestock breeds, Ecol. Econ. 3 (2003) 377-392.

[24] Smith C., Economic benefits of conserving animal genetic resources, Anim. Genet. Res. Info. 3 (1984) 10-14.

[25] Smith C., Estimated costs of genetic conservation in farm livestock, Animal genetic resources conservation by management, data banks and training, FAO animal production and health paper 44 (1984) 21-30.

[26] Smith C., Genetic aspects of conservation in farm livestock, Livest. Prod. Sci. 11 (1984) 37-84.

[27] Thaon d'Arnoldi C., Foulley J.L., Ollivier L., An overview of the Weitzman approach to diversity, Genet. Sel. Evol. 30 (1998) 149-161.

[28] Weitzman M.L., On diversity, Quart. J. Econ. CVII (1992) 363-405.

[29] Weitzman M.L., What to preserve? An application of diversity theory to crane conservation, Quart. J. Econ. CVIII (1993) 157-183.

[30] Weitzman M.L., The Noah's Ark Problem, Econometrica 66 (1998) 1279-1298.

[31] Wilson R.T., Central Mali - Cattle Husbandry in the Agropastoral System, World Anim. Rev. 58 (1986) 23-30.

[32] Wilson R.T., Clarke S.E., Studies on the Livestock of Southern Darfur, Sudan: II. Production Traits in Cattle, Trop. Anim. Health Prod. 8 (1976) 47-51.

[33] World Bank, World Development Indicators 2001: Relative prices and exchange rates, World Bank, Washington, 2003. http//www.worldbank.org/data/icp/documents/Table5_7.pdf [consulted: 6 November 2003].

To access this journal online: www.edpsciences.org 